

\title{
Biomechanical Characteristics of Microimplant for Anchorage in Orthodontics: A 3D Finite Element Model Study
}

\author{
D Lakshmayya Naidu, T Harini, CMS Krishna Prasad, H Vidyadhara Lakshmi, NK Lokesh, HS Dharmesh
}

\begin{abstract}
In orthodontic treatment, anchorage control is essential for success. A recent development, stationary anchorage (microimplants) eliminates one of the uncertainties of orthodontic tooth movement by offering absolute control over potentially undesirable counter movements. The objective of this study was to establish a 3D finite element model for microimplant and to analyze the influence of different angulations to the long axis of the teeth $\left(30-90^{\circ}\right)$ on the biomechanical characteristics of orthodontic anchorage implant-bone interface. Results of this study showed that largest stress and deformation was seen in the cortical bone and upper region of trabecular bone. Stress and deformation increased as the angulations of the implant to the long axis of the tooth increased. As the angulation of the implant to the long axis of maxillary 1st molar increased, stress and deformation also decreased. Maximum stress and displacement were recorded when implant was placed perpendicular to the long axis of maxillary 1 st molar.
\end{abstract}

Keywords: Anchorage, Microimplants, Finte element model.

How to cite this article: Naidu DL, Harini T, Prasad CMSK, Lakshmi HV, Lokesh NK, Dharmesh HS. Biomechanical Characteristics of Microimplant for Anchorage in Orthodontics: A 3D Finite Element Model Study. J Contemp Dent Pract 2013;14(6):1076-1079.

\section{Source of support: Nil}

Conflict of interest: None

\section{INTRODUCTION}

In orthodontic treatment, anchorage control is essential for success. ${ }^{1}$ If there is an imbalance of force, unwanted tooth movement occurs. A recent development, stationary anchorage (microimplants) eliminates one of the uncertainties of orthodontic tooth movement by offering absolute control over potentially undesirable counter movements.

Load transfer from implants to surrounding bone depends on the (A) type of loading, (B) the bone-implant interface, (C) the length and diameter of the implants, (D) the shape and characteristics of the implant surface and (E) the quantity and quality of the surrounding bone.

In the past two decades, finite element analysis (FEA) has become an increasingly useful tool for the prediction of the effects of stress on the implant and its surrounding bone.

A key factor for the success or failure of a dental implant is the manner in which stresses are transferred to the surrounding bone.

Finite element analysis allows us to predict stress distribution in the contact area of the implants with cortical bone and around the apex of the implants in trabecular bone (Figs $1 \mathrm{~A}$ and $\mathrm{B})^{2}$

One of the main use of implants is to retract anteriors in maximum anchorage cases.

Implants are usually placed at $30^{\circ}$ to $60^{\circ}$ angulations to long axis of the teeth. This will improve retention while reducing the risk of striking a root. ${ }^{3-6}$

\section{OBJECTIVES}

To establish a three-dimensional (3D) finite element model (FEM) for microimplant and to analyze the influence of different angulations to the long axis of the teeth $\left(30-90^{\circ}\right)$ on the biomechanical characteristics of orthodontic anchorage implant-bone interface.

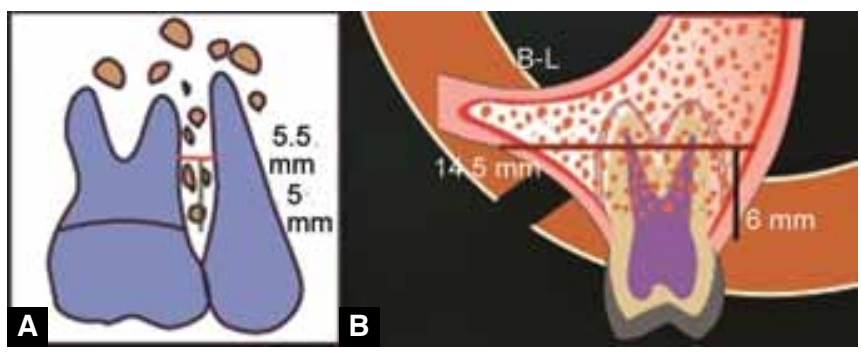

Figs 1A and B: (A) Position of microimplant between 2nd premolar and 1st molar (B) cortical surface thickness of $2 \mathrm{~mm}$, 3D finite element model (FEM) of micro-implant 


\section{MATERIALS AND METHODS}

Three-dimensional models from implant and bone were generated to analyze anchorage load.

Computations of stress arising in the implant bone interface was made with FEA using NISA-II, Display-III marketed by EMRC (Engineering Mechanics Research Corporation) - A 3D computer software.

A model of orthodontic implant measuring $1.2 \mathrm{~mm}$ diameter and $8 \mathrm{~mm}$ in length was generated (Fig. 2).

The results were recorded during static loading in the bone around the implant.

The implant was simulated at the following angulations$30,45,60$ and $90^{\circ}$ (Fig. 3) to the long axis of the max 1st molar. A simulated orthodontic force, which was 200 gm loaded mesiodistal (MD) to the mathematical model (Figs 4A and B). The stress and displacement on the implant-bone interface were analyzed.

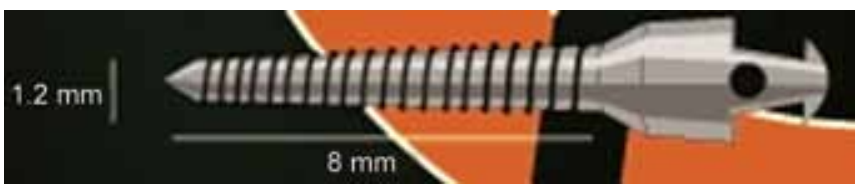

Fig. 2: Miniscrew implant

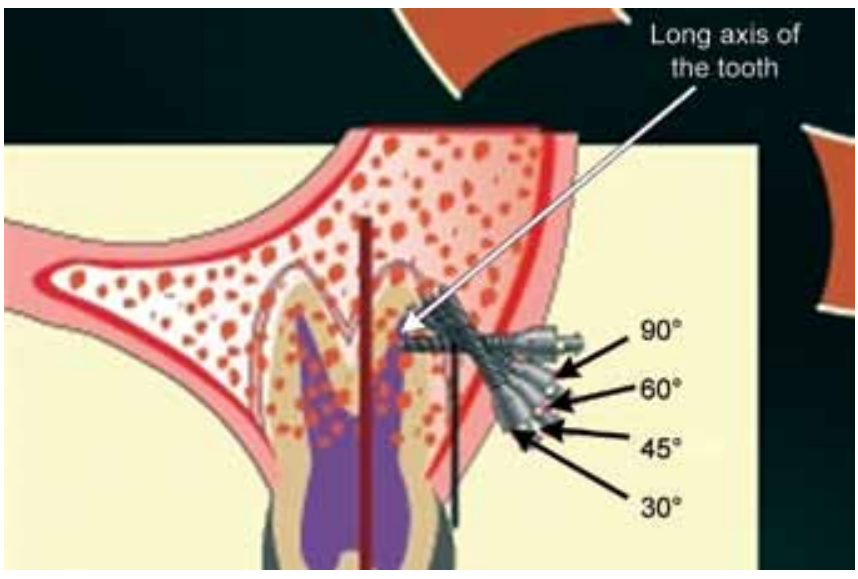

Fig. 3: Implant bone interface at different angulations

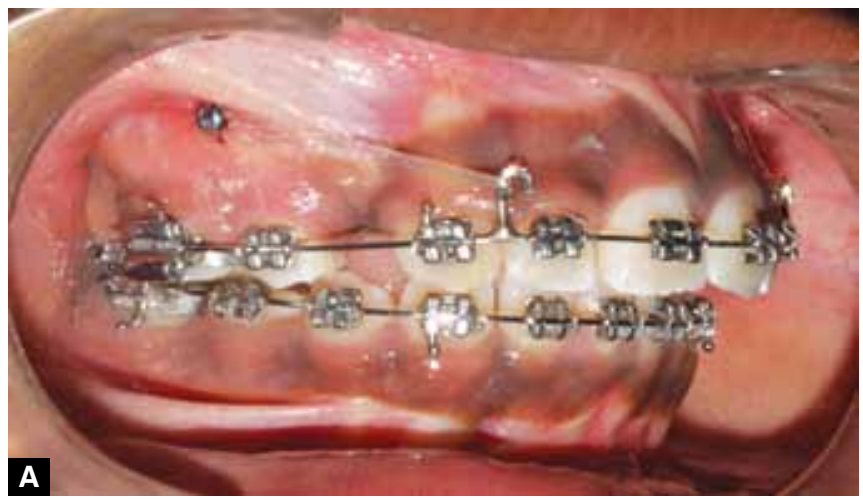

\section{RESULTS}

\section{Stress Distribution (Fig. 5)}

- Interface - when placed $90^{\circ}$ to mid sagittal plane, stress at cortical bone is $15.91 \mathrm{Mpa}$ and, on trabecular bone, it is $7.96 \mathrm{Mpa}$ for 3 to $4 \mathrm{~mm}$.

- Interface-when placed $60^{\circ}$ to mid sagittal plane, stress at cortical bone is $15.91 \mathrm{Mpa}$ and, on trabecular bone, it is $7.96 \mathrm{Mpa}$ for 3 to $4 \mathrm{~mm}$.

- Interface - when placed $45^{\circ}$ to mid sagittal plane, stress at cortical bone is $7.698 \mathrm{Mpa}$ and, on trabecular bone, it is $5.132 \mathrm{Mpa}$ for 3 to $4 \mathrm{~mm}$.

- Interface - when placed $30^{\circ}$ to mid sagittal plane, stress at cortical bone is $7.703 \mathrm{Mpa}$ and, on trabecular bone, it is $5.135 \mathrm{Mpa}$ for 3 to $4 \mathrm{~mm}$.

As the angulation decreased, the stress at the cervix of the implant were decreased.

\section{Displacement of Implant (Fig. 6)}

1. Interface-when placed $90^{\circ}$ to mid sagittal plane, displacement at cortical bone is $-9.444 \times 10.4$ and on trabecular bone, it is $-5.632 \times 10.4 \mathrm{Mpa}$ for 3 to $4 \mathrm{~mm}$.

2. Interface - when placed $60^{\circ}$ to mid sagittal plane, displacement at cortical bone is $-9 \times 10.4$ and, on trabecular bone, it is $-5.401 \times 10.4 \mathrm{Mpa}$ for 3 to $4 \mathrm{~mm}$.

3. Interface - when placed $45^{\circ}$ to mid sagittal plane, displacement at cortical bone is $-8.8 \times 10.4$ and, on trabecular bone, it is $-5.215 \times 10.4 \mathrm{Mpa}$ for 3 to $4 \mathrm{~mm}$.

4. Interface - when placed $30^{\circ}$ to mid sagittal plane, stress at cortical bone is $-8.5 \times 10.4$ and, on, trabecular bone, it is $-5.039 \times 10.4 \mathrm{Mpa}$ for 3 to $4 \mathrm{~mm}$.

The largest stress and deformation was seen in the cortical bone and upper region of trabecular bone. Stress and deformation increased as the angulations of the implant to the long axis of the tooth increased.

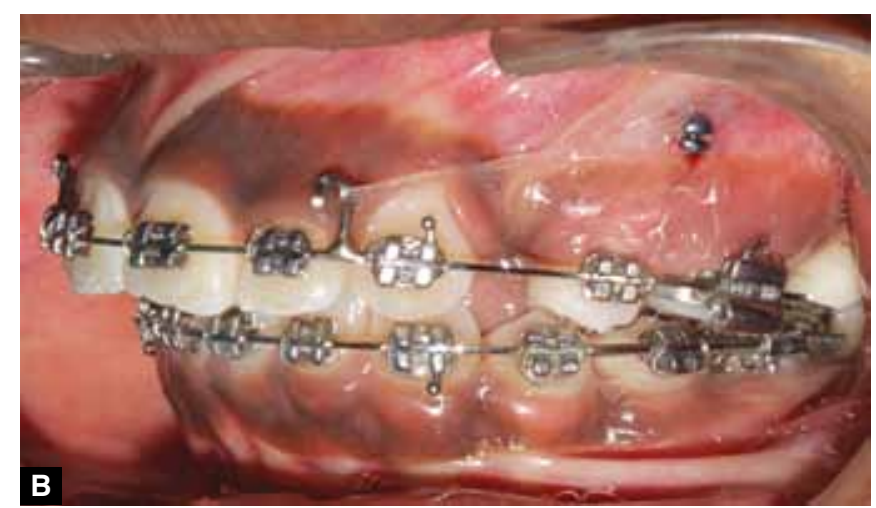

B

Figs 4A and B: Retraction of teeth using implants 


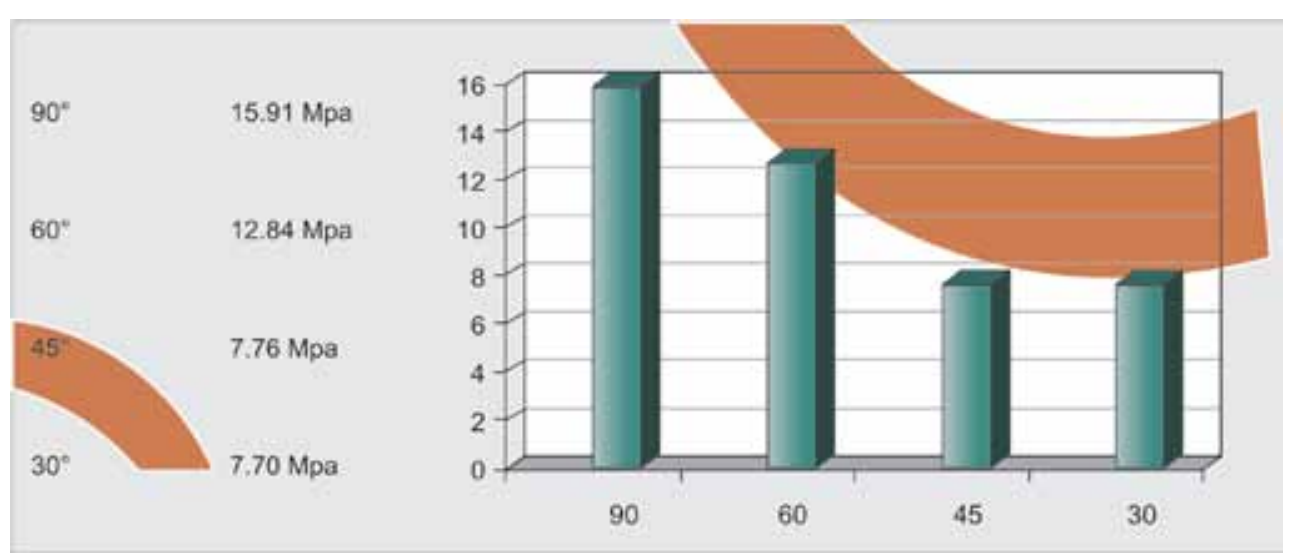

Fig. 5: Stress distribution at different angulation of implant

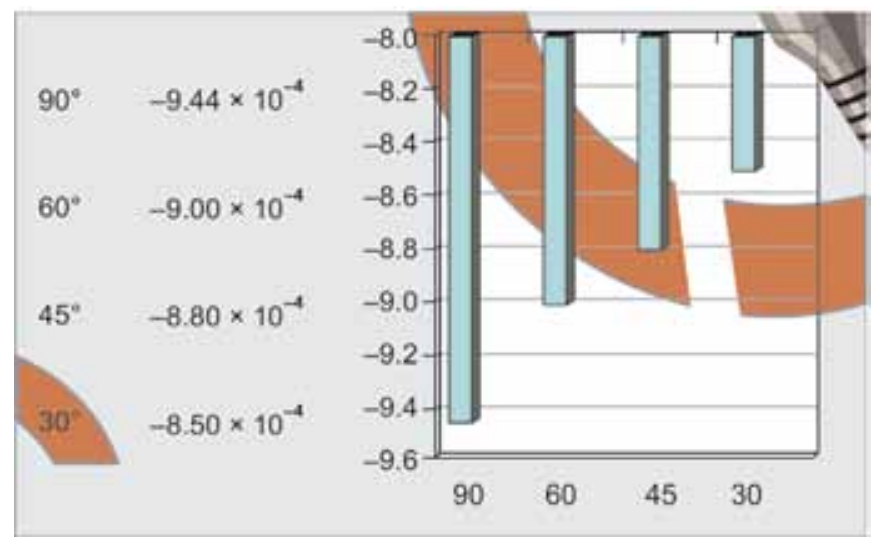

Fig. 6: Displacement of implant at different angulations

\section{DISCUSSION}

The aim of the present study was to investigate the deformation of the bone surface around an implant in response to force application in different angulation of implant placement.

Abnormally high stress concentration in the supporting tissues can result in pressure necrosis and, subsequently, in implant failure. ${ }^{7}$

Finite element models were used to evaluate the load transfer from the mini-screw to the surrounding bone.

The primary component of the load transfer takes place at a single revolution of the miniscrew thread with in the cortex.

Under the assumed loading condition, the miniscrew is displaced in a tipping mode, causing tensile stress in the direction of the force. ${ }^{8-11}$

In general, stress levels are higher in the cortical bone than in the trabecular bone.

The thickness of the cortical bone determines the overall load transfer from the miniscrew to bone and stiffness of the trabecular bone plays only a minor role.

The cortical surfaces of the maxilla are thinner and less compact than those of the mandible.

The finite element (FE) method was adapted largely to clinical conditions by selecting parameters, such as implant and bone shape, stress and its angulations.
By applying the FE method, the influence of different angulations to the long axis of the max 1st molar was observed. ${ }^{12,13}$

\section{CONCLUSION}

Microimplants can be safely loaded with 200 gm of MD orthodontic force. As the angulation of the implant to the long axis of max 1st molar increased stress and deformation also decreased.

Maximum stress and displacement were recorded when implant was placed perpendicular to the long axis of max 1 st molar.

\section{REFERENCES}

1. Fontenelle A. Lingual bracket orthodontics: another approach. OrthodFr 1986;57:541-557.

2. Melsen B, Petersen JK, Costa A. Zygoma ligatures: an alternative form of maxillary anchorage. J Clin Orthod 1998 Mar;32(3): 154-158.

3. Roberts WE. Bone dynamics of osseointegration, ankylosis and tooth movement. J Indiana Dent Assoc 1999 Fall;78(3): 24-32.

4. Wehrbein H, Glatzmeier J, Mundwiller U, Diedrich P. The Orthosystem: a new implant system for orthodontic anchorage in the palate. J Orofac Orthop 1996 Jun;57(3):142-153. 
5. Sugawara J, Daimaruya T, Umemori M, Nagasaka H, Takahashi I, Kawamura H, Mitani H. Distal movement of mandibular molars in adult patients with the skeletal anchorage system. Am J Orthod Dentofacial Orthop 2004 Feb;125(2):130-138.

6. Miyawaki S, Koyama I, Inoue M, Mishima K, Sugahara T, Takano-Yamamoto. Factors associated with the stability of titanum screws placed in the posterior region for orthodontic anchorage. Am J Orthod Dentofacial Orthop 2003 Oct;124(4): 373-378.

7. Costa A, Raffainl M, Melsen B. Miniscrews as orthodontic anchorage: a preliminary report. Int J Adult Orthod Orthognath Surg 1998;13(3):201-209.

8. Deguchi T, Takano-Yamamoto T, Kanomi R, Hartsfield JK Jr, Roberts WE, Garetto LP. The use of small titanium screws for orthodontic anchorage. J Dent Res 2003;82(5):377-381.

9. Melsen B, Costa A. Immediate loading of implants used for orthodontic anchorage. Clin Orthod Res 2000 Feb;3(1):23-28.

10. Melsen B, Lang NP. Biological reactions of alveolar bone to orthodontic loading of oral implants. Clin Oral Impl Res 2001 Apr;12(2):144-152.

11. Meyer U, Wiesmann HP, Fillies T, Joos U. Early tissue reaction at the interface of immediatly loaded detal implants. Int J Oral Maxillofac Implants 2003;18(4):1-11.

12. Majzoub Z, Finotti M, Miotti F, Giardino R, Aldini NN, Cordioli G. Bone response to orthodontic loading of endosseous implants the rabbit calvaria: early continuous distalization forces. Eur J Orthodontics 1999 Jun;21(3):223-230.

13. Favero L, Brollo P, Bressan E. Orthodontic anchorage with specific fixtures: Related study analysis. Am J Orthod Dentofacial Orthop 2002 Jul;122(1):84-94.

\section{ABOUT THE AUTHORS}

\section{Lakshmayya Naidu (Corresponding Author)}

Principal, Professor and Head, Department of Orthodontics and Dentofacial Orthopedics, KLR's Lenora Institute of Dental Sciences Rajanagaram, Rajahmundry, Andhra Pradesh, India, Phone: 09848021412, e-mail: drdlnaidu@rediffmail.com

\section{T Harini}

Reader, Department of Orthodontics, Army College of Dental Sciences Secunderabad, Andhra Pradesh, India

\section{CMS Krishna Prasad}

Senior Lecturer, Department of Orthodontics, Army College of Dental Sciences, Secunderabad, Andhra Pradesh, India

\section{H Vidyadhara Lakshmi}

Assistant Professor, Department of Orthodontics, Government Dental College and Hospital, Hyderabad, Andhra Pradesh, India

\section{NK Lokesh}

Reader, Department of Orthodontics, Rajarajeswari Dental College Bengaluru, Karnataka, India

\section{HS Dharmesh}

Senior Lecturer, Department of Orthodontics, Rajarajeswari Dental College, Bengaluru, Karnataka, India 